\title{
SELECTION OF THE MATHEMATICAL MODEL FOR THE USE OF ENROFLOXACIN IN CATS
}

\author{
Galya Shivacheva, Miroslav Vasilev \\ Faculty of Technics and Technologies, Trakia University \\ 38 Graf Ignatiev str., 8602, Yambol, Bulgaria, \\ e-mail: galya.shivacheva@trakia-uni.bg
}

\begin{abstract}
The process of changing the concentration of enrofloxacin in blood plasma in cats after single intravenous injection was identified by three mathematical models - algebraic and two models represented respectively by a first order differential equation and a second order differential equation. In order to select the best model of the three, the Akaike information criterion corrected is used. With the most identification parameters differs the model based on a second-order differential equation. The lowest value of the Akaike information criterion corrected was also obtained with it. This fact gives reason to choose it for the best model for describing the research process.
\end{abstract}

Keywords: mathematical model, identification, enrofloxacin, Akaike's information criterion, Korelia.

\section{INTRODUCTION}

Enrofloxacin is a broad-spectrum antibacterial drug officially registered and authorized for use in veterinary medicine. It belongs to the so-called "second generation" of fluorinated quinolones [2,3]. In [7], the change in the concentration of enrofloxacin in the blood plasma of cats was monitored by comparing the dynamic parameters of the drug's pharmacokinetics with three methods of administration. For each of the routes of treatment: single intravenous and subcutaneous injection of a substance of enrofloxacin hydrochloride and internal tablet administration, algebraic equations are drawn up. They are solutions of first-order differential equations.

The purpose of this study is to select a mathematical model to describe the process of changing the concentration of enrofloxacin in blood plasma in cats after a single intravenous injection. To realize it, identification was made using three mathematical models - algebraic [7], first-order differential and second-order differential. The choice was made using the corrected Akayke information criterion and the number of identification parameters was analyzed.

\section{MATERIAL AND METHODS}

The experimental design and data acquisition methodology are presented in [3]. Identification used their mean and standard deviation.

\subsection{Software used}

Data processing and analysis are carried out using the specialized software from the KORELIA family. The user-oriented interface [9] and the process recognition module [10,11] facilitate data entry and support the selection of a mathematical model. The identified equations [13] can be analyzed and compared over a number of parameters [8] and thus found to be the most appropriate for the particular set [12].

IRTIIE Vol. 7, No. 4, 2019 ISSN 1314-8788 (print), ISSN 1314-8796 (online), doi: 10.15547/artte.2019.04.006 


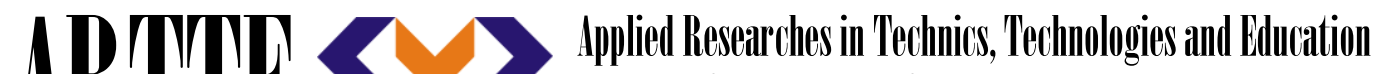 Journal of the Faculty of Technics and Technologies, Trakia University https://sites.google.com/a/trakia-uni.bg/artte/}

The quadratic error minimization criterion is applied for optimization. The coefficient of determination $R^{2}$ was used to estimate the proximity of the identified parameters to the experimental data for each model.

Due to the existence of three models described with different equations, it is not permissible for their closeness to the data to be estimated by the coefficient of determination. Akaike information criterion (AIC) is suitable for this case $[1,5,12]$.

When the number of information points $\mathrm{N}$ is small compared to the number of identification parameters $\mathrm{K}\left(\frac{N}{K}<40\right)$, it is necessary to use the corrected version of the Akaike information criterion corrected, AICc [4,6]. If $\mathrm{N} \rightarrow \infty$ the values of the two criteria converge.

In cases where the AICc results are very similar, additional model evaluation criteria have to be used. Probability of the model $\left(P_{I, J}\right)$ can be calculated from AICc.

$$
\begin{aligned}
P_{I, J} & =\frac{1}{1+e^{0.5 \Delta_{I, J}}} \\
\text { where: } \quad \Delta_{I, J} & =A I C c_{I}-A I C c_{J} \\
I, J & - \text { numbers of compared models }
\end{aligned}
$$

For the purpose of comparison, the proof coefficient (Evidence ratio - $\mathrm{ER}_{\mathrm{I}, \mathrm{J}}$ ), which is the ratio of the reliability of two compared models in the form:

$$
E R_{I, J}=\frac{P_{I, J}}{P_{J, I}}=e^{-0.5 \Delta_{I, J}}
$$

\subsection{Mathematical models}

Three mathematical models have been identified.

\subsubsection{Algebraic Model (Model 1)}

In [2] describes in detail the algebraic model used, which is a solution of a first-order differential equation.

$$
\mid \begin{aligned}
& y(t)=\left(C_{0}-C_{\infty}\right) \cdot e^{-r \cdot t}+C_{\infty} \\
& C_{\infty}=\lim _{t \rightarrow \infty} y(t)=\frac{K \cdot U}{r}
\end{aligned}
$$

where: $\mathrm{U}(\mathrm{t})-\mathrm{a}$ dose of enrofloxacin

$\mathrm{C}_{0}$ - initial value

Identification parameters are:

$r-$ the rate constant of the process;

$K$ - coefficient of sensitivity. 


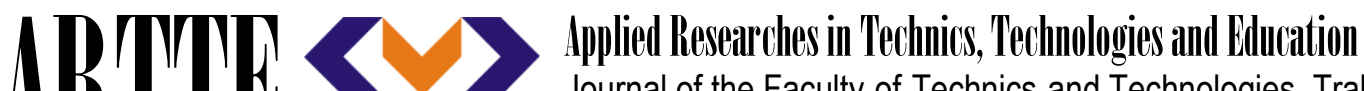 Journal of the Faculty of Technics and Technologies, Trakia University https://sites.google.com/a/trakia-uni.bg/artte/}

\subsubsection{Differential first-order model (Model 2)}

$$
\mid \begin{aligned}
& \frac{d y(t)}{d t}+r \cdot y(t)=K \cdot U(t) \\
& \mathrm{y}(0)=\mathrm{C}_{0}-\text { initial value }
\end{aligned}
$$

where: $U(t)$ - a dose of enrofloxacin

Identification parameters are:

$$
\begin{aligned}
& r-\text { the rate constant of the process; } \\
& K-\text { coefficient of sensitivity. }
\end{aligned}
$$

\subsubsection{Second-order differential model (Model 3)}

It is represented by the equation:

$$
\mid \begin{aligned}
& \frac{d^{2} y(t)}{d t^{2}}+2 \cdot \zeta \cdot \omega \cdot \frac{d y(t)}{d t}+\omega^{2} y=K \cdot \omega^{2} \cdot U(t) \\
& \mathrm{y}(0)=\mathrm{C}_{0} \quad \text { initial conditions } \\
& \frac{d y(0)}{d t}=0
\end{aligned}
$$

where: $U(t)-$ a dose of enrofloxacin

Identification parameters are:

$$
\begin{aligned}
& \zeta \text { - damping ratio; } \\
& \omega \text { - natural frequency; } \\
& \mathrm{K} \text { - coefficient of sensitivity. }
\end{aligned}
$$

\section{RESULTS AND DISCUSSION}

The identification parameters for each of the three models were calculated using the KORELIA-Ident program. The following equations are derived from them:

Model 1

$$
y(t)=1.34 \cdot e^{-0.42 t}+0.10
$$

Model 2

$$
\frac{d y(t)}{d t}-0.39 . y(t)=0
$$

Model 3

$$
\frac{d^{2} y(t)}{d t^{2}}+93.71 \frac{d y(t)}{d t}+47.06 y=-28.24
$$




\section{IRTTIE}

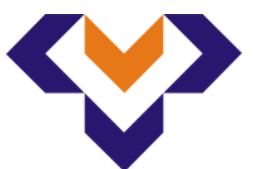

Ipplied Resseirlohes in Technics, Technologies and Bductation

Journal of the Faculty of Technics and Technologies, Trakia University https://sites.google.com/a/trakia-uni.bg/artte/

Figure 1 shows the graphs of the models.

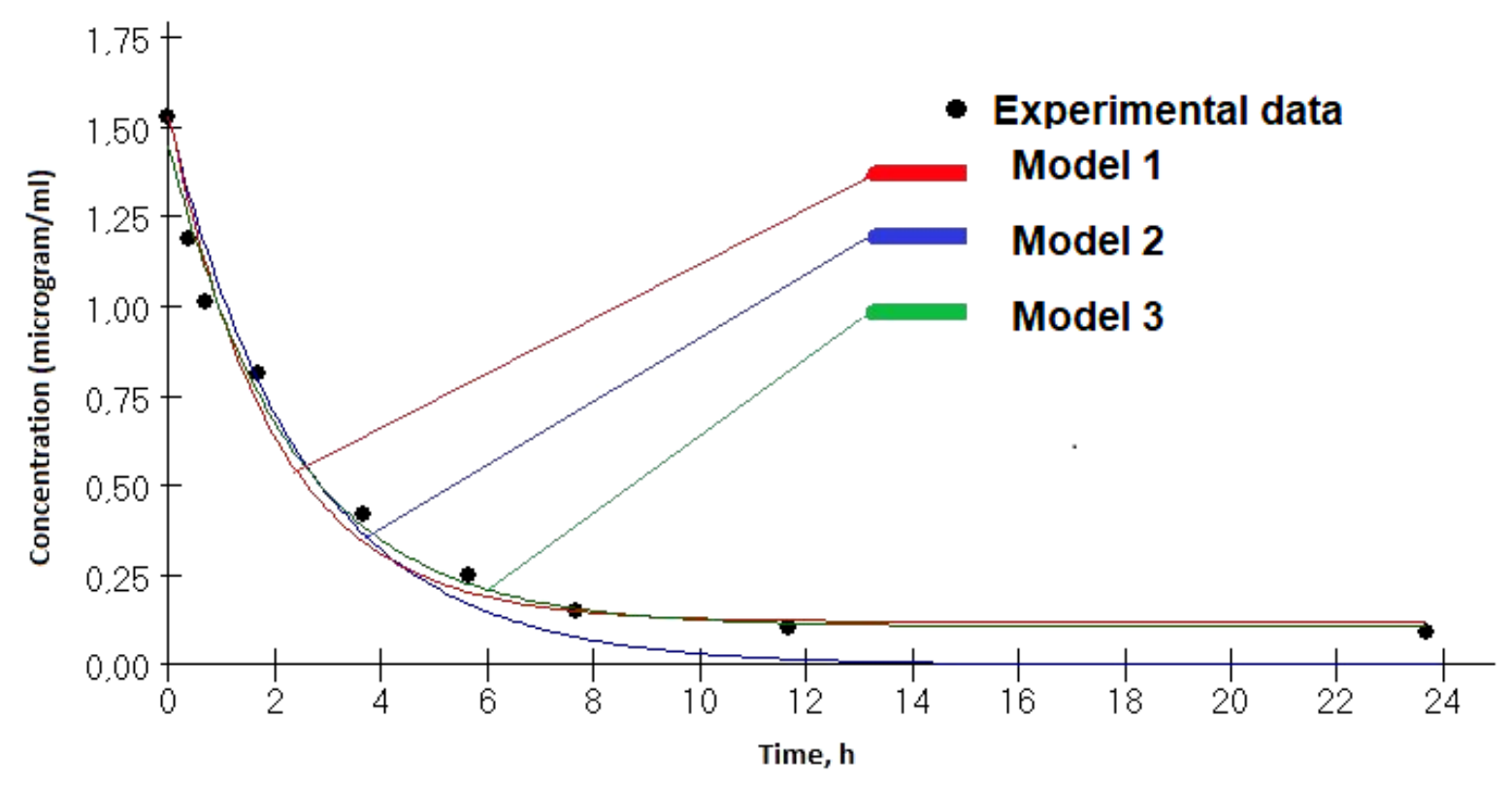

Figure 1.

Change in enrofloxacin concentration in the three models

The parameters used to compare the three mathematical models are presented in Table 1. To calculate the reliability of the model and the coefficient of proof are formulas (1) and (2) used. The calculations are done with Excel. The values for $R^{2}$, quadratic error and AICc were obtained by identifying with the KORELIAldent program. A corrected version of AIC was used to select a model from all three reasons the relatively similar values of $\mathrm{N}$ and $\mathrm{K}$ in the process studied.

Table 1. Comparison of models after identification

\begin{tabular}{|c|c|c|c|c|c|c|c|}
\hline Model & $\begin{array}{c}\text { Number of } \\
\text { identification } \\
\text { parameters }\end{array}$ & $\mathrm{R}^{2}$ & $\begin{array}{c}\text { Quadratic } \\
\text { error }\end{array}$ & $\mathrm{AICc}$ & $\Delta \mathrm{AICc}$ & $\mathrm{P}_{\mathrm{I}, \mathrm{J}}$ & $\mathrm{ER}_{\mathrm{I}, \mathrm{J}}$ \\
\hline $\begin{array}{c}\text { Model } \\
3\end{array}$ & 3 & 0,980 & 0,045 & -2304 & & & \\
\hline $\begin{array}{c}\text { Model } \\
1\end{array}$ & 2 & 0,987 & 0,030 & -2192 & 112 & $6,7917 \mathrm{E}-25$ & $1,47239 \mathrm{E}+24$ \\
\hline $\begin{array}{c}\text { Model } \\
2\end{array}$ & 2 & 0,964 & 0,082 & -2151 & 153 & $5,53578 \mathrm{E}-34$ & $1,80643 \mathrm{E}+33$ \\
\hline
\end{tabular}

The best model according to the AICc criterion is the one with the smallest value. The fulfillment of this condition is the second-order differential model - Model 3. The values of $\mathrm{P}_{\mathrm{I}, \mathrm{J}}$ and $\mathrm{ER}_{\mathrm{I}, \mathrm{J}}$ show that the three models differ from each other. 


\section{CONCLUSION}

The process of change in the concentration of the drug enrofloxacin in the blood plasma of cats after a single intravenous injection was identified by three mathematical models algebraic, first-order differential and second-order differential. The corrected Akayke information criterion was used to select the "optimal" model. Its lowest value is obtained in a mathematical model based on a second order differential equation and different from the other two with more identification parameters - three in number.

\section{ACKNOWLEDGEMENTS}

The study was supported by scientific project No. 2. FTT/ 31.03.2017 "Research of systems and processes using the phase plane method "of the Faculty of Engineering and Technology Technology of Yambol, Tracia University of Stara Zagora.

The authors are grateful to Prof. Dr. Dimitrichka Dimitrova, University of Forestry, Sofia for the experimental data provided.

\section{REFERENCES}

[1] Anderson D., K. Burnham. (1999). Understanding Information Criteria for Selection Among Capture-Recapture or Ring Recovery Models. Bird Study. Vol. 46, Suppl. 1999. pp. 14-21.

[2] Bratoev N., A. Milanova, D. Dimitrova, R. Moutafchieva, Iv. Pavlova, and L. Lashev. (2017). The pharmacokinetics of enrofloxacin in ducks with steatosis after force-feeding. Veterinarski Arhiv, 87 (2), 2017, ISSN 0372-5480, pp. 209-219.

[3] Dimitrova D. (2013). Comparative study of the pharmacokinetics of enrofloxacin in dogs and cats. Pharmacokinetics of some antimicrobial chemotherapeutics in veterinary medicine. Litera print, Stara Zagora, 2013, pp. 93-101. (in Bulgarian).

[4] Hamparsum Bozdogan. (2000). Akaike's Information Criterion and Recent Developments in Information Complexity. Journal of Mathematical Psychology, 44, 2000, pp. 62-91.

[5] Motulsky H. J., A Christopoulos. (2003). Fitting models to biological data using linear and nonlinear regression. A practical guide to curve fitting. GraphPad Software Inc. 2003, p. 351.

[6] Mavrevski R., M., B. Yurukov. (2015). Steps in modeling of biological data with GraphPad Prism, Workshop "Mathematical Modelling and Scientific Computing" MMSC2015, December 09-11, 2015, Velingrad, Bulgaria.

[7] Shivacheva G., D. Dimitrova, M. Vasilev. (2015). Dynamic parameters for assessment of the pharmacokinetics of enrofloxacin to cats. ARTTE Vol. 3, No. 2, 2015 ISSN 13148788 (print), 1314-8796 (online), pp. 174-182.

[8] Yankov K. (2015). Assessment of Processes Using Identification Models. Applied Researches in Technics, Technologies and Education ARTTE, Vol. 3, No. 1, 2015. ISSN 1314-8788 (print), ISSN 1314-8796 (online). pp. 52-60. doi: 10.15547/artte.2015.01.006.

[9] Yankov K., D. Ilieva. (2015). User Interface for Analysis of Experimental Data. Trakia Journal of Sciences, Vol. 13, Suppl. 1, pp. 420-425, 2015 ISSN 1313-7069 (print), ISSN 1313-3551 (online). doi:10.15547/tjs.2015.s.01.072.

[10] Yankov K. (2010). Decision Planning of System Identification. Proc. of the Int. Conference on Information Technologies (InfoTech-2010). St. St. Constantine and Elena resort, Sept. 16-18, 2010, Varna, Bulgaria, pp. 229-238. ISSN 1314-1023. 
[11] Yankov K. (2009). Recognition and Function Association of Experimental Data. Proc. of the Int. Conference on Information Technologies (InfoTech-2009). St. St. Constantine and Elena resort, Sept. 17-20, 2009, Varna, Bulgaria, pp.131-140.

[12] Yankov K. (2015). Selection of the Approximating Function for Isobologram Modeling. Proc. Int. Conference on Information Technologies (InfoTech-2015). St. St. Constantine and Elena resort, Varna, Bulgaria, Sept. 17-19, 2015, pp. 174-183. ISSN 1314-1023.

[13] Yankov K. (2006). System Identification of Biological Processes. Proc. 20-th Int. Conf. "Systems for Automation of Engineering and Research (SAER-2006). St. St. Constantine and Elena resort, Sept. 23-24, 2006, Varna, Bulgaria, pp. 144-149. ISBN 954-438-575-4. 